كيفية تناول موتسارت لصوت السويرانو في مقطوعة الراحة الأبدية من القداس الجنائزي ومتطلبات أداءه

شيماء محمد عز الدين الحداد'

$$
\begin{aligned}
& \text { أ.د / عنايات وصفي } \\
& \text { أ.د / ماجد صموئيل إبراهيم" } \\
& \text { مقدمة: - }
\end{aligned}
$$

اهتمت الكنبسة الكاثوليكية في أوروبا وعلى وجه الخصوص في إيطاليا بتقديم أنواع كثيرة من

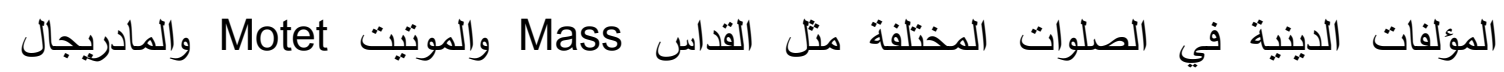
Madrigal

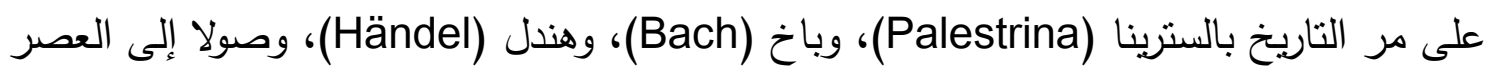

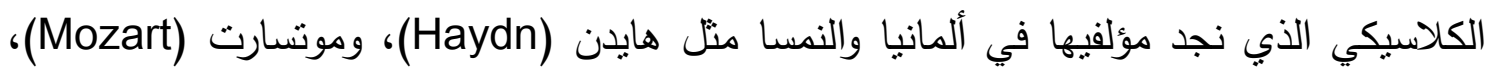

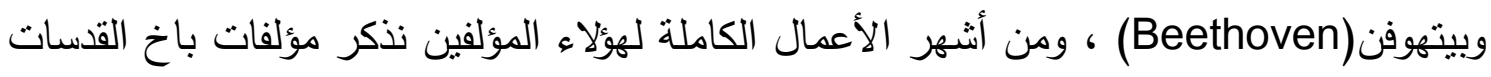

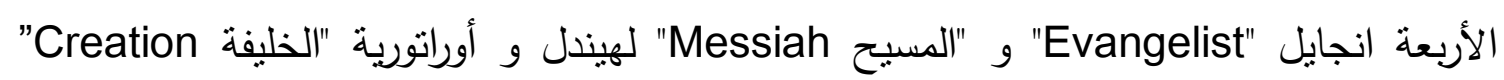
لهاديدن و "القداس الصغير Petite mass Solemn" لروسيني (Rossini) كما أهتم قليل من المؤلفين أيضا بتأليف قداس خاص يقدم في الصلاة على الموتى ويسمي

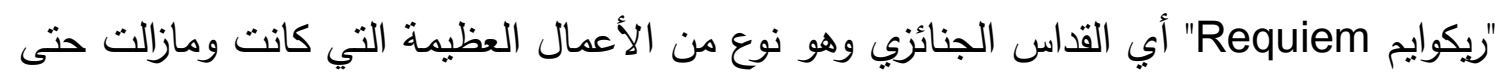

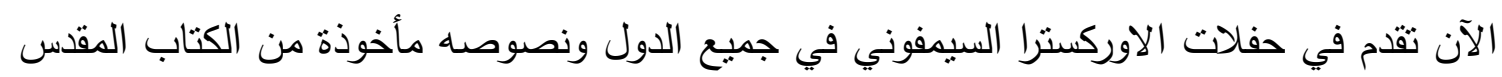
ويعد موتسارت Mozart من أهم مؤلفي القداس الجنائزي وهو موضون فئرع البحث الحئ الحالي.

' باحثة بمرحلة الدكتوراة بقسم الأداء - شعبة غناء - كلبة التربية الموسيقية- جامعة حلوان

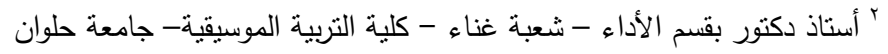

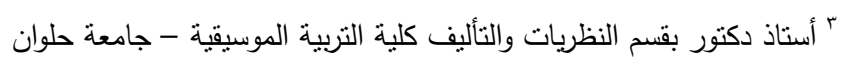

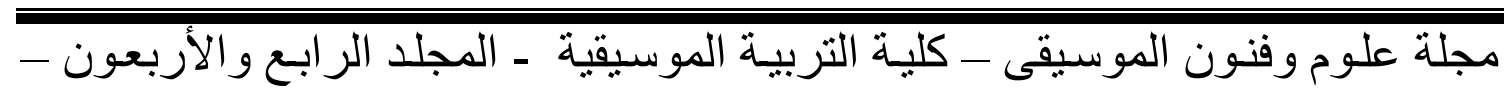

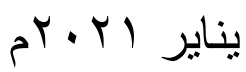


يعتبر القداس الجنائزي "Requiem" من أهم المِلفات الدينية التي ألفها مونسارت، وقد توفي

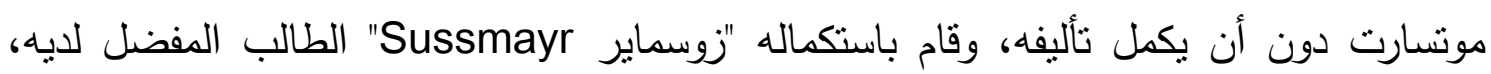

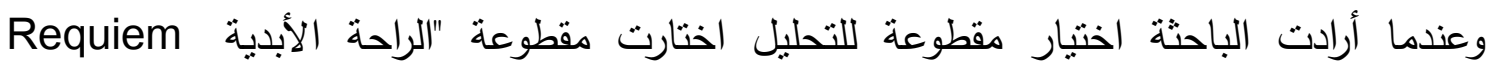
aeternam

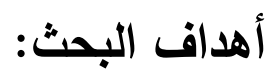

ا التعرف على كيفية تأليف موتسارت لصوت السوبرانو في مقطوعة "الراحة الأبدية Requiem aeternam

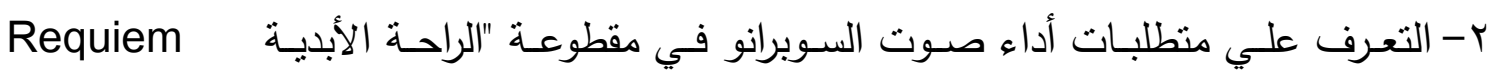
aeternam أسئلة البحث:

Requiem ما هو أسلوب موتسارت في التأليف لصوت السوبرانو في مقطوعة "الراحة الأبدية aeternam ץ-ماهي متطلبات أداء صوت السوبرانو في مقطوعة "الراحة الأبدية Requiem aeternam" في

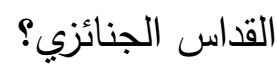
أدوات البحث: أثنتملت أدوات البحث على: المدمونات الموسيقية- الأسطوانات المدمجة للأعمال- أسطوانات فيديو - شبكة الإنترنت.

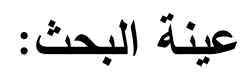
مقطوعة الراحة الأبدية Requiem aeternam (chor, Soprano i) عيكهة مصطلحات البحث:

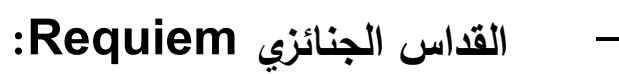

مجلة علوم وفنون الموسيقى - كلية التربية الموسيقية ـ المجلد الر ابع و الأربعون -

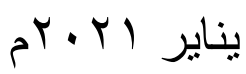


نوع من التأليف الغنائي الكنسى, يدخل ضمن خدمات الكنيسة, ويؤدي في مناسبات الوفاة أو

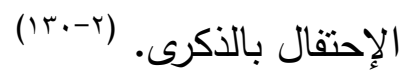

\section{- -}

كلمة يونانية الأصل, وتعني في اللغة اليونانية الطبقة الأرسقراطية المثقفة, وتعني الكلاسيكية في

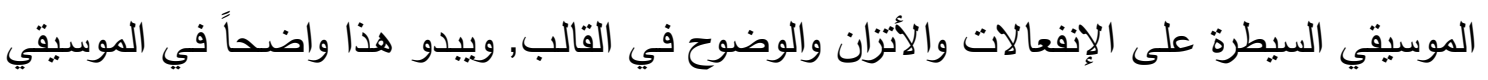

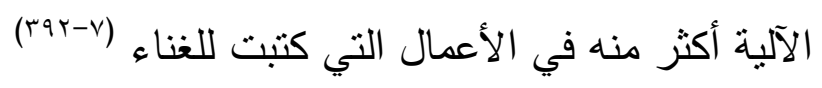

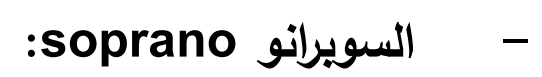

يرجع أصل كلمة سوبرانو إلى كلمة إيطالية وهي "sopra" وهي تعني أعلى أو فوق وفي الأصوات

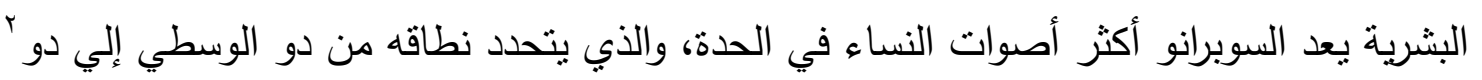
والأصوات المدربة يمكنها تخطي هذه الدساحة بقليل من النغمات الأحد وينقسم السوبرانو

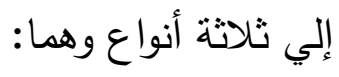

سوبرانو درامي soprano dramatic سوبرانو شاعري soprano lyric سري دري سوبرانو خفيف Soprano coloratura (10-0) سويرو شاعب الاراسات السابقة المرتبطة بموضوع البحث:

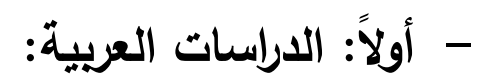

الدراسة الأولي بعنوان "دراسة تحليلية لأسلوب أداء ثنائيات السويرانو في قداس باخ " في سلم سي الصغير" تتاول هذا البحث أسلوب ثثائيات السوبرانو في قداس باخ في سلم سي الصغير وخصائص

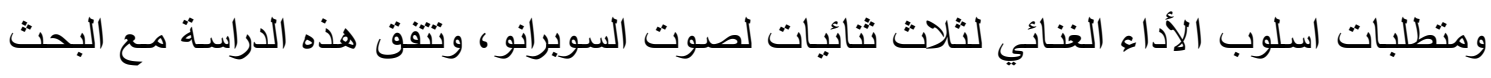

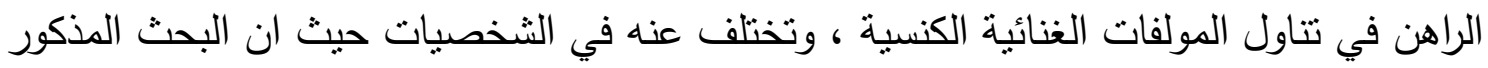
تتاول باخ ولكن البحث الحالي تتاول موتسارت.

مجلة علوم وفنون الموسيقى - كلية التربية الموسبقية ـ المجلد الر ابع و الأربعون -

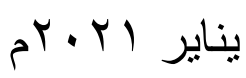




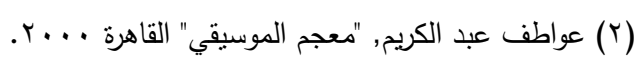

( $\vee$ C Christine Ammer: dictionary of music: $4^{\text {th }}$ edition, 2004, by 1992 trust facctson,inc,ny 10001.

\section{الاراسة الثانية بعنوان:}

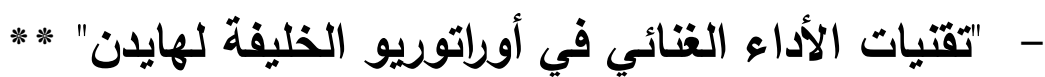

تتاولت هذه الدراسـة القاء الضـوء علي مؤلفة "أوراتوبو الخليقة" لهايدن وتتاولها بالدارسـة

والتحليـل والوقوف على أهـ خصـائص وأسـلوب أدائها وتذليل بعض الصـعوبات التكنيكيـة في مي أغنيتين منها، تتفق هذه الدراسـة مـع البحث الراهن من حيث تتـاول احد أنواع الموسيقى الدينيـة الكنائسية ويختلف معها في الثخصية.

- مانياً الدراسات الأجنبية: - ماثية الاراسة الثالثة بعنوان:

\section{* I VA T أوراتوريو موسم الصوم لهيندل من عام -}

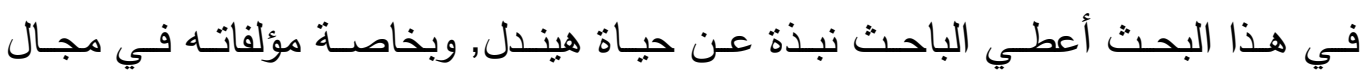
الأوراتوريو , كما تكلم عن أسلوب أداء الأوراتوريو من خـلال عرض بعض النمـاذج لـه, وأظهر العلامات المميزة في هذه المؤلفات وطرق أدائها.

رأت الباحثة تشابها بين هذا البحث والبحث الراهن في تتاول أحد أنواع الموسيقي الدينية الكنائسية ولكنه أختلف عنه في الحقبة الزمنية والثخصية التي تتاولها حيث أن هذا البحث تتاول هيندل بينما البحث الراهن تناول موتسارت.

(๑) Appel will: Harvard dictionary of music, liedi, Combridge, London, 1972.

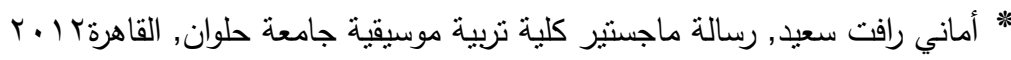

$$
\begin{aligned}
& \text { * * عهود عبدالحليم أحمد, بحث منشور , مجلة علوم وفنون الموسيقي, القاهرة ع .. بام. }
\end{aligned}
$$

مجلة علوم وفنون الموسيقى - كلية التربية الموسيقية ـ المجلد الر ابع و الأربعون -

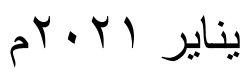




\section{المفاهيم النظرية المرتبطة بالبحث:}

\section{أولاً: القداس}

القداس هو الخدمة الرئيسية في الكنيسة الكاثوليكية التي تحمي ذكرى العشاء الأخير وموت

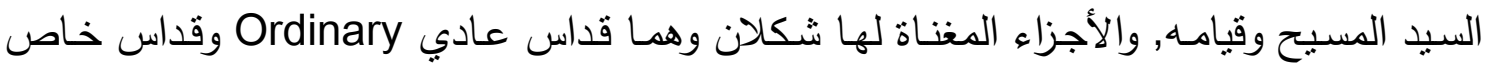
Proper

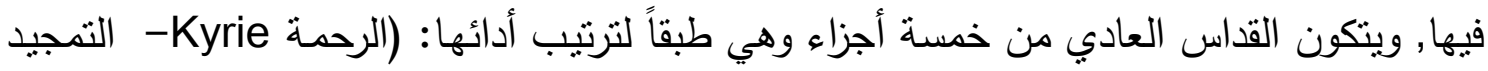
-Gloria

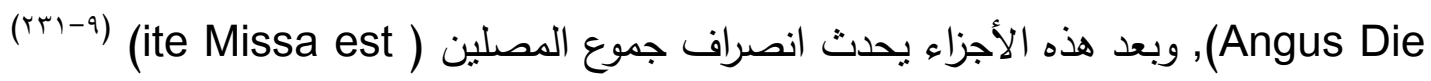
وتغني هذه الأجزاء طوال السنة ماعدا تمجيد الربGloria الذي يغني في أيام الأحساد

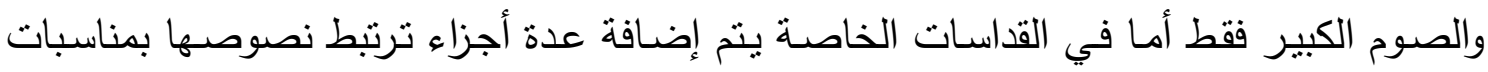

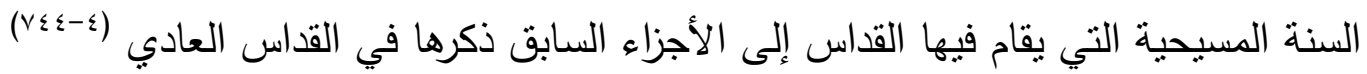
القداس الجنائزي لموتسارت

القداس الجنائزي (باللاتينية Requiem Mass) وهو عمل موسيقي كبير بدأ موتسارت في تأليفه سنة |V9 | في فيينا ، وتقول بعض كتب التاريخ أن رجلا غامضا طرق باب موتسارت وطلب منه تأليف قداس جنائزي وانصرف الرجل دون أن بعلم موتسارت من هو ، ومن ثم يقال أن مونسارت

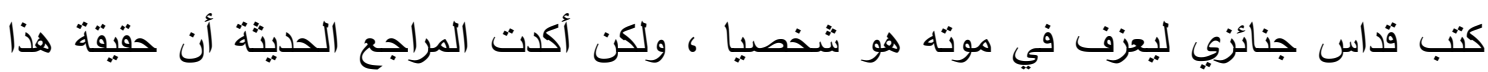

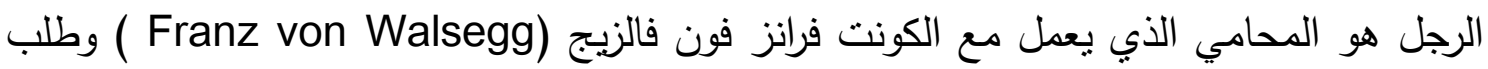

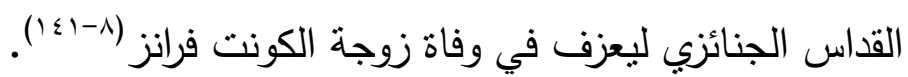

* Young, Percy. The Oratorios of Handel. London: D. Dobson, January 1949.

(9) Richard Bekar: The Hamlyn illustrated encyclopedia of music, edited by Alan Tsaacs\& Elizabeth Marten, The Hamlyn Publishing group, limited 1982,1990.

(4) Alison Latham: The Oxford companion of music, Oxford university Press,2002, New York.

مجلة علوم وفنون الموسيقى - كلية التربية الموسيقية ـ المجلد الر ابع والأربعون -

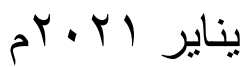


Wolfgang Amadeus Mozart (1756-1791) ثنانيا : فولفجانج أماديوس موتسارت

حياته ولد موتسارت عام VOT بمدينة سالزبورج بالنمسا في أسرة موسيقية حيث كان والده ليوبولد (Maria Anna) عازفه للبيانو وقد علمه والده الموسيقى والعزف على آلة الكلافيير فتمكن من العزف عليها وهو في الثالثة من عمره؛ ثم بدأ

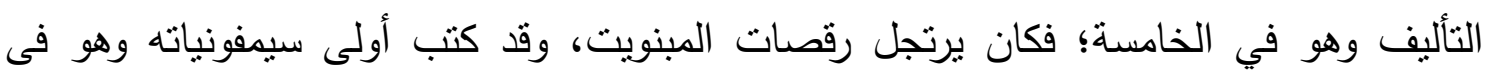

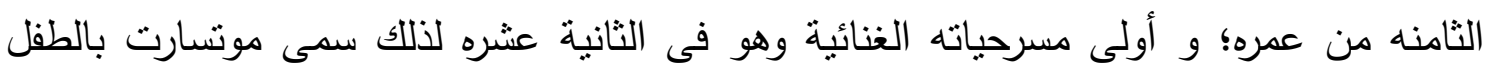

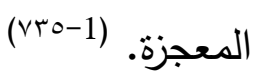

اتسعت موهبة مونسارت بعد ذلك في التأليف خاصة المقطوعات الصغيرة للكلاضيير وكان يقوم بعزفها. وفى عام IVII طاف به والده بلدان أوربا لإقامة العديد من الحفلات الموسيقية لعزف هذه

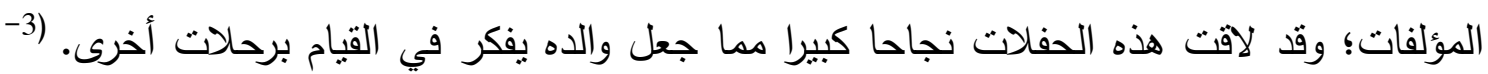

قام موتسارت بعدة رحلات الى إيطاليا وفرنسا والنمسا وانجلترا وقابل باخ الذي تأثز بمؤلفاته، كما

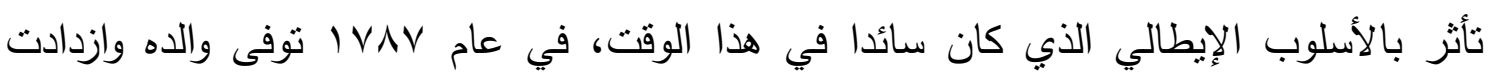
متاعبه المالية فعاد الى فيينا وهو في حالة صحية ونفسية سيئة وتوفى موتسارت في ه ديسمبر لإني

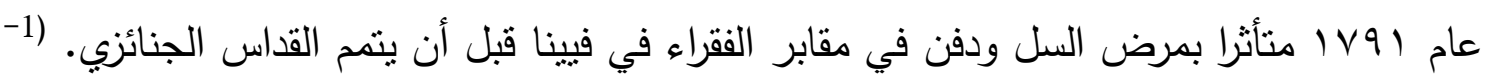
$(\varepsilon \varepsilon$.

(8) Daniel N. Leeson: THE Story of the Mozart Requiem, Opus Ultimum! Second Edition, Algora publishing, 2012, New York, p.141

(1) ثيودور • م. فيني : تاريخ الموسيقى العالمية، ترجمة سمحة الخولي وجمال عبد الرحيم، دار المعارف، القاهرة سنة بr9Vا م.

مجلة علوم وفنون الموسيقى - كلية التربية الموسيقية ـ المجلد الر ابع والأربعون - 
-

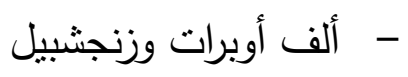
- ألف للالات المختلفة (بيانو - فيولينه - باصون - كلارنيت - هورن - فلوت ) وذلك بشكل

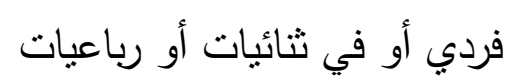
- الف للأوركسترا سيمفونيات وعدد كبير من الكونشبرنت للألات المختلفة .

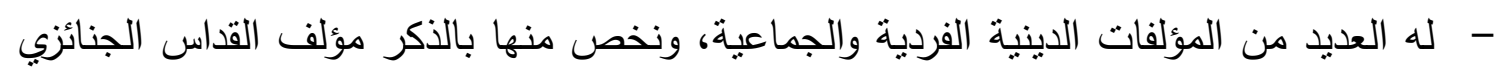

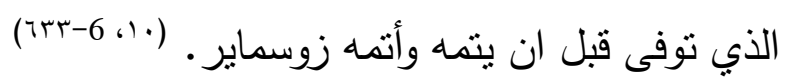

ثالثا: الدراسة التحليلية

سوف تقوم الباحثة بالتحليل الغنائي لأغنية الراحة الأبدية Requiem aeternam من القداس

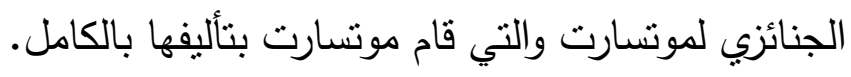

Requiem aeternam مقطوعة الراحة الأبدية

الأغنية هيا فاتحة القداس وقد ألفها موتسارت للكورال مع غناء فردي لصوت السوبرانو بمصاحبة مجموعة كبيرة من الآلات الوترية والنحاسية وغيرها.

(1) ثيودور • م. فيني : تاريخ الموسيقى العالمية، ترجمة سحة الخولي وجمال عبد الرحيم، دار المعارف، القاهرة سنة بلو 19 م.

« ص

( ·.)Encyclopedia Della Musica 1v , Rizzoli Ricordi , Milano , 1963 - 1964

(6) Blom Eric (Edit.): Groves's Dictionary of Music and Musicians, 5th Ed., London, 1954, Macmillan, 1887, p. 633

مجلة علوم وفنون الموسيقى - كلية التربية الموسبقية ـ المجلد الر ابع و الأربعون - 
كلمات المقطوعة باللغة اللاتينية واللغة العربية: Requiem aeternam Requiem aeternam dona eis, Domine, فلتمنحهم يا سيدي الراحة الأبدية Requiem aeternam dona eis Domine سيدي هم فلتمنح الأبدية الراحة

Et lux perpetua lucaet eis. و ليسطع النور الأبدي عليهم Et Lux perpetualucaet eis عليهم ليسطع الأبدي النور و

Te decet hymnus Deus, in Sion, و لتصبح يا إلهي ترنيمة في صهيون Te Decet hymnus Deus in Sion صهيون في يا إلهي ترنيمة لتصبح و

Et tibi reddetur votum in Jerusalem;

و لتصل إليك القرابين في أورشليم Et Tibi reddeturvotum in Jerusalem أورشليم في القرابين لتصل إليك و

Exaudi orationem meam, فلتسمع دعائي

Exaudi Orationemmeam ي د دعاء لتسمع

مجلة علوم وفنون الموسيقى - كلية التربية الموسبقية ـ المجلد الر ابع و الأربعون -

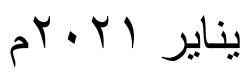


Ad te omnis caro veniet

$$
\text { إليك يذهب كل جسد }
$$

Ad Te Omnis caro veniet

يذهب جسد كل ـ ـ إلى

كانون Canon

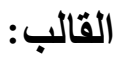

بدأ بسلم رى الصغير ثم سلم فان

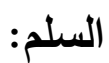

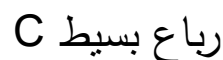

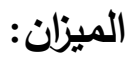

بطى

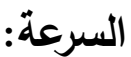

المساحة الصوتية لصوت السويرانو: صول - فا'

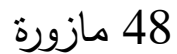

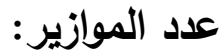

الأصوات المشتركة فى الغناء: اء

سوبرانو Soprano - ألطو - Alto - تينور Basso - باص

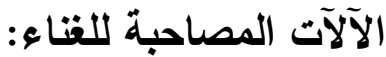

- Trombe in D آلة الكورنو Corni di Bassetto آلة الفاجوت Fagotti - آلة النرومبا آلة التيبنانى Timpani in D - A آلات فيولينو أول Violin OI آلات فيولينو ثانى . Basso Organo أورغون - Violoncello نتيللو - Violino II

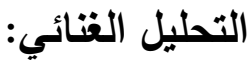

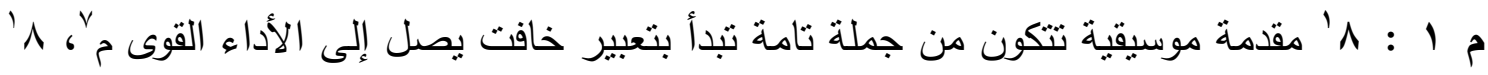

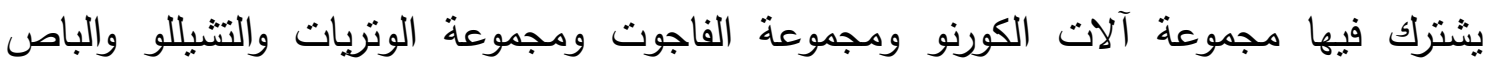
والأرغن. - مان.

مجلة علوم وفنون الموسيقى - كلية التربية الموسيقية ـ المجلد الر ابع و الأربعون -

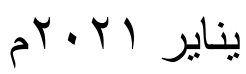


بينما تعزف آلات الكورنو والفاجوت ألحانا ذات تسلسل سلمى صاعد وهابط فى أداء مترابط، تعزف الآلات والأرغن نغمات متفرقة مستخدمة إيقاع الروش فقط وسكتاته، ولكن عند آلات الفيولينو

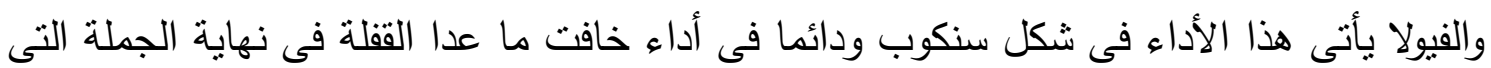

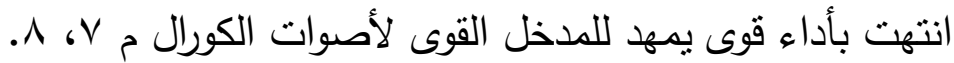

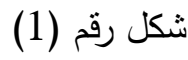

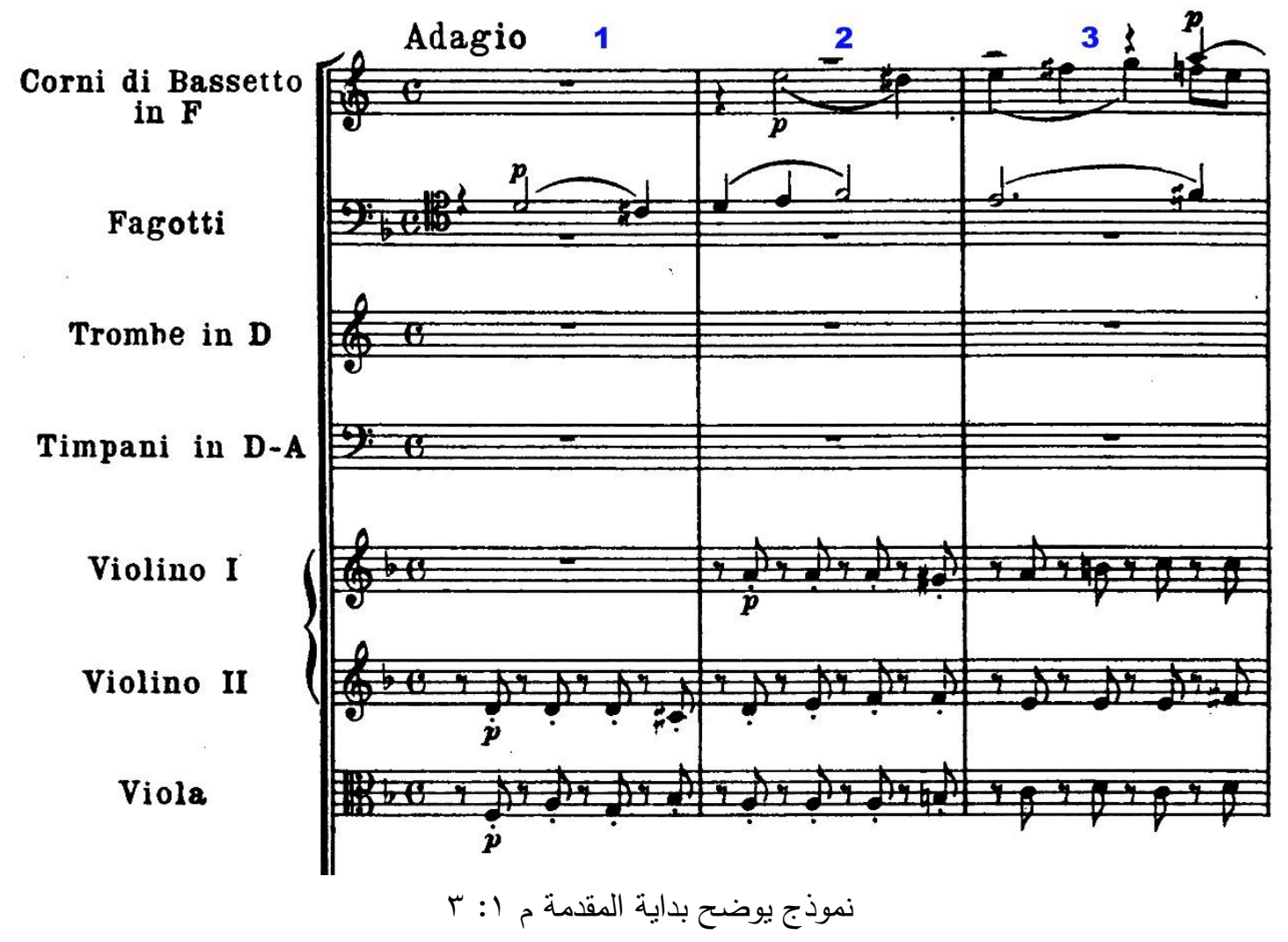

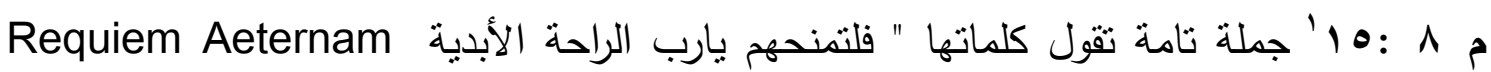
dona eis Domine

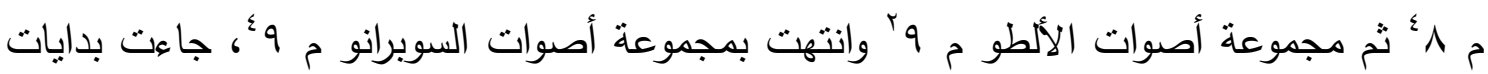
الأصوات بطريقة الكانون وبكلمات موحدة (السابقة) وتغنت جميع هذه الأصوات بأداء قوى.

et Lux 19 19 19 عبارة مطولة وجاءت على كلمات " وليسطع النور الأبدى عليهم Perpetua Lucaet eis

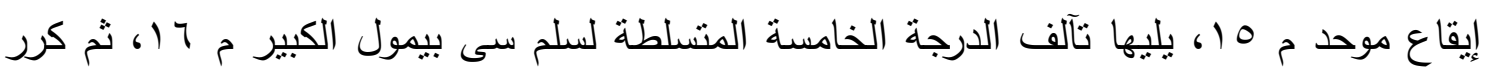

مجلة علوم وفنون الموسيقى - كلية التربية الموسيقية ـ المجلد الر ابع والأربعون -

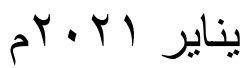




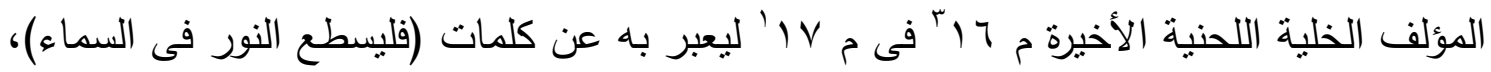

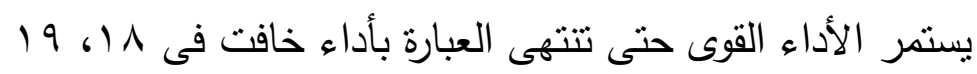

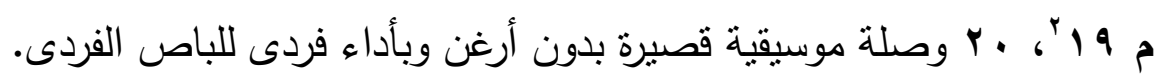

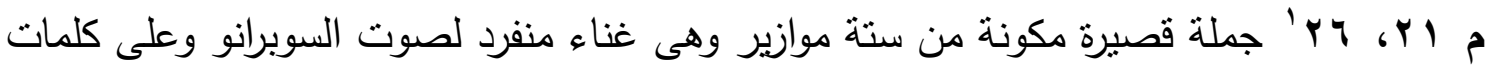

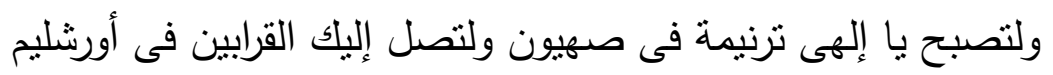

Te decet hymnus Deus, in Sion, et tibi reddetur votum in Jerusalem" حيث يبدأ من هنا ولأول مرة ظهور لصوت السوبرانو الفردى، بدأ السوبرانو فى نفس نآلف نهاية

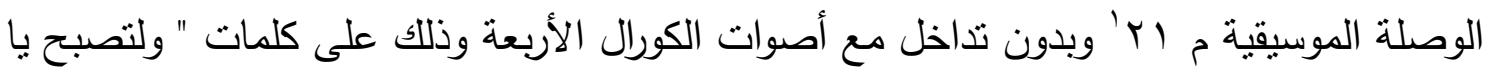

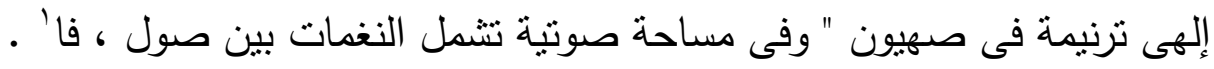
بدأ اللحن فى المنطقة الحادة لصوت السوبرانو مستخدما مسافة الثالثة الصغيرة الصاعدة والهابطة رى': فا': رى' ثم استمر بتسلسل سلمى صاعد وهابط تعبيرا عن دعاء يمثل الكلمات الآتية " ولتصبح يا إلهى ترنيمة فى صهيون " فى أنثال إيقاعية لا تتعدى النوار والكروش.

شكل رقد (r) (
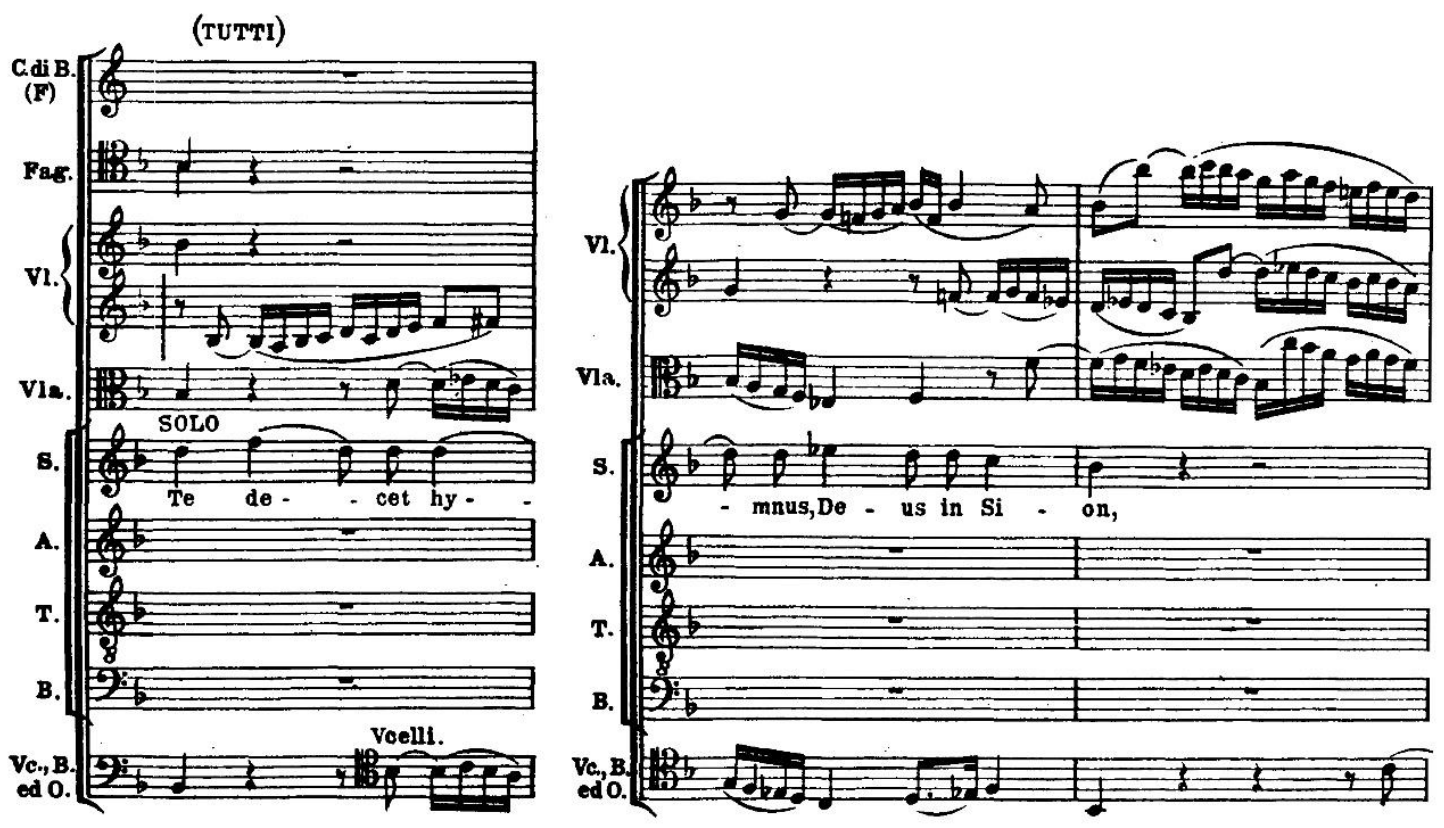

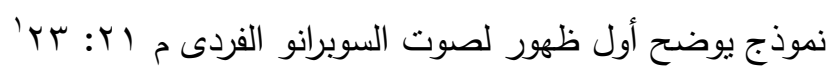

م ؟ ب بعد عدة سكتات يبدأ اللحن بنغمة دو' ومنها إلى رى' ثم يهبط بمسافة خامسة تامة رى':

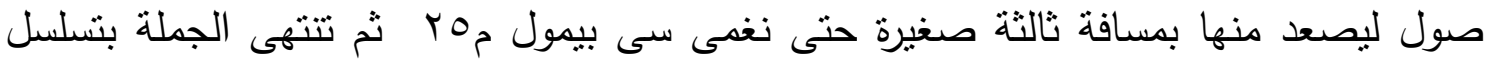

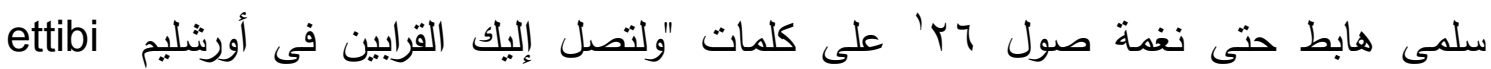
مجلة علوم وفنون الموسيقى - كلية التربية الموسيقية ـ المجلد الرابع و الأربعون - 
reddetur votum in Jerusalem

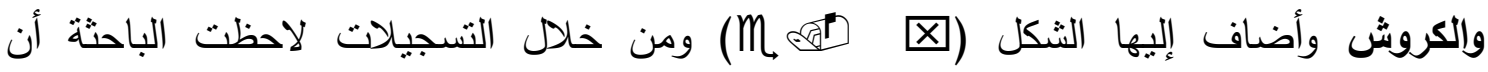
السوبرانو أدت هذه الجملة بأداء قوى.

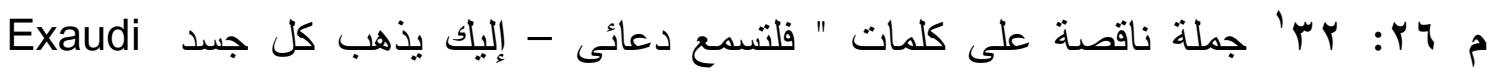
. " Orationem meam, ad te owinis Caro Veniet

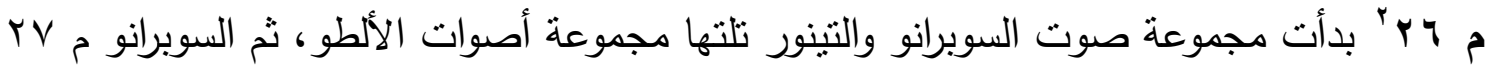

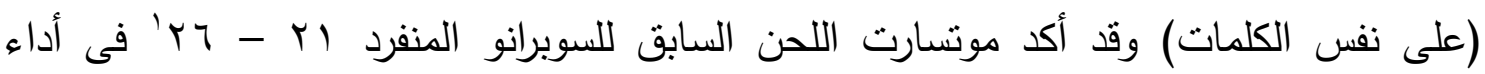

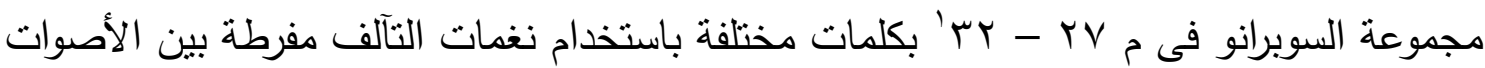
المختلفة وذلك بأداء قوى وبققلة تامة فى سلم سى بيمول الكبير • تغنت جميع الأصوات بقوة بثلاث نغمات حتى صوت التينور وثلاث نغمات حتى صوت الباص

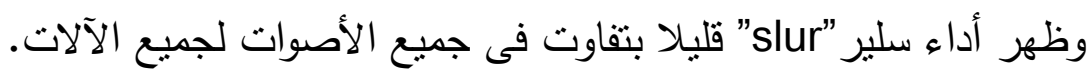

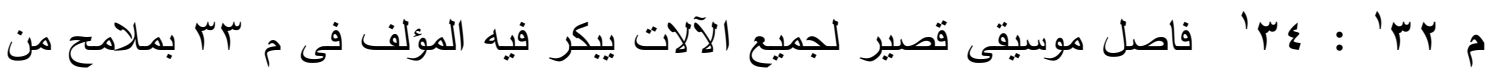

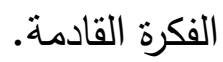

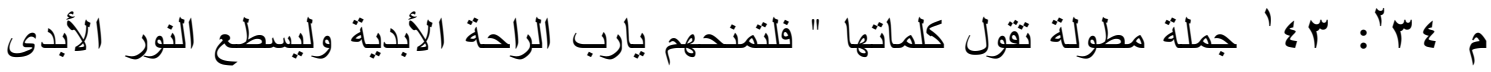

Requiem aeternam dona eis, Domine, Et Lux Perpetua Lucaet eis " عليهز النيه يبدأ فيها الباص بكلمة " الراحة Requiem " ثم يبدأ موتسارت فى مؤلف فوجالى صميم يبدأ فيه

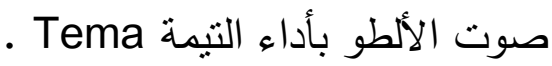

مجلة علوم وفنون الموسيقى - كلية التربية الموسيقية ـ المجلد الر ابع و الأربعون -

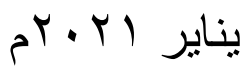




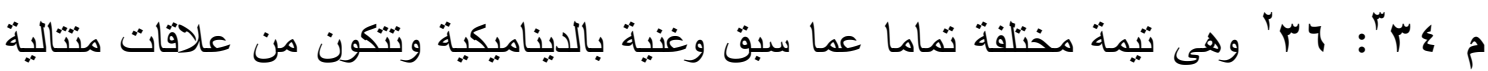

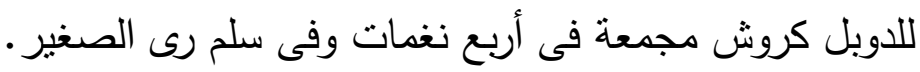

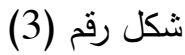
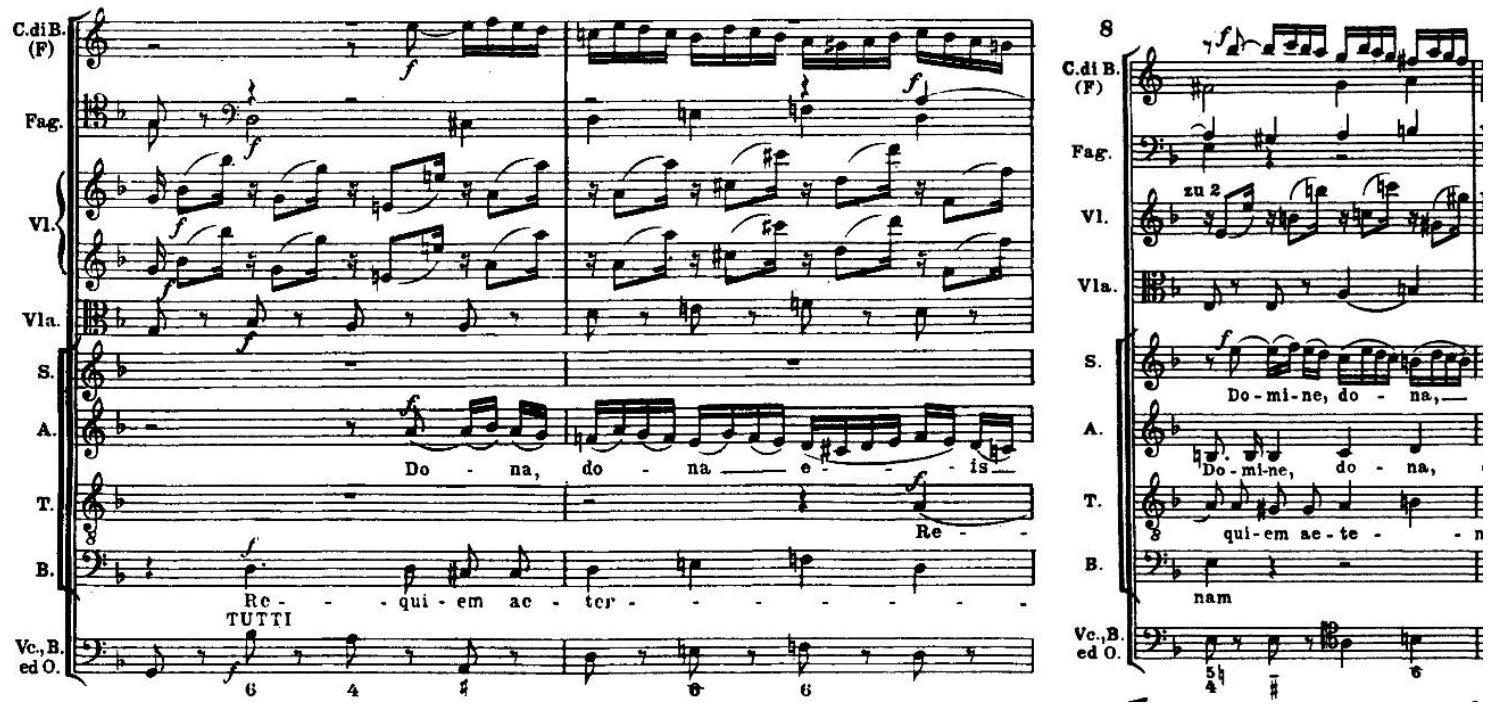

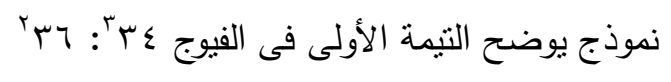

צr': ^ץ' يأتى مدخل السوبرانو منداخلا مع نهاية مدخل الألطو فى بr' فى سلم لا الصغير

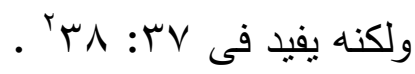

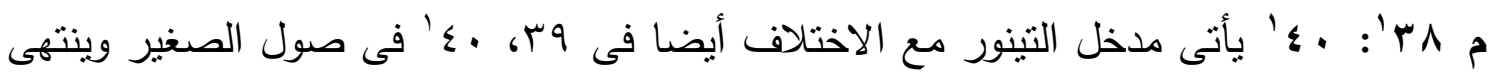
على الدرجة الخامسة فى فا الكبير.

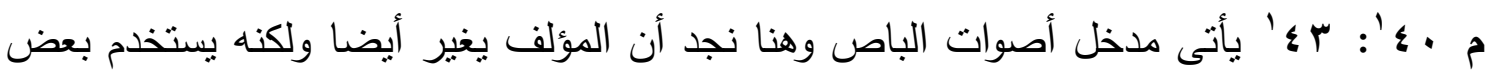
خلايا التيمة ويكررها متتقلا من سلم فا الكبير إلى سلم رى الصغير وينتهى بسلم صول الصغير. وهنا ينتهى الجزء الفوجالى الرائع الذى تساند فيه الأصوات ببعض النغمات كما نساهم بعض

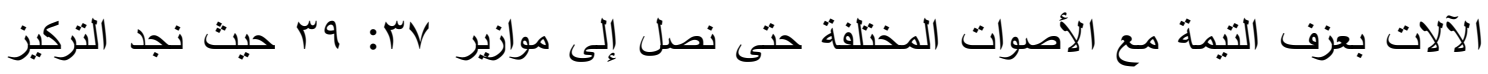

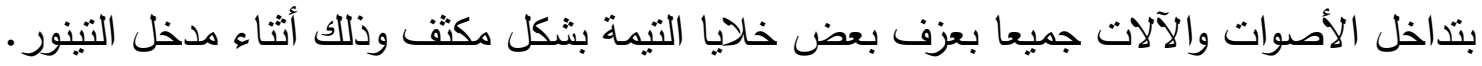

مجلة علوم وفنون الموسيقى - كلية التربية الموسيقية ـ المجلد الرابع والأربعون -

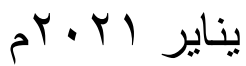




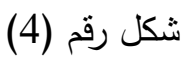

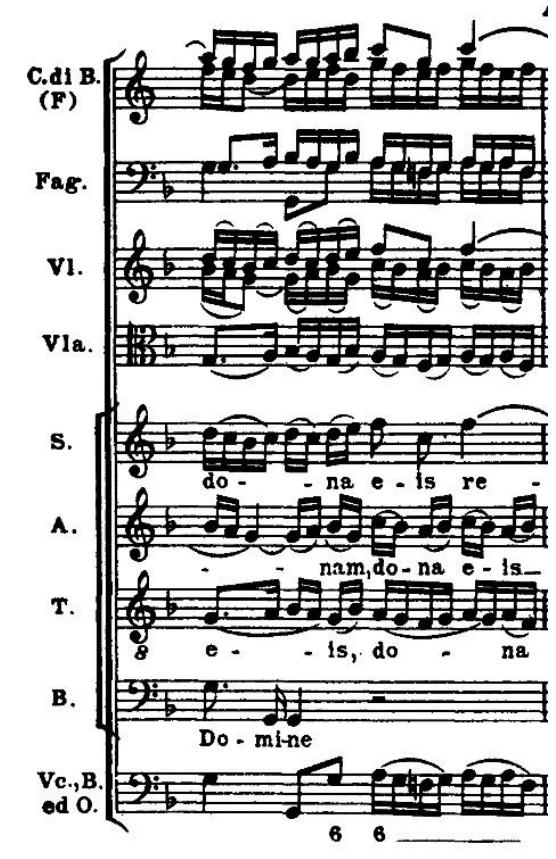

$$
\text { نموذج يوضح النكيف فى جميع الأصوات والآلات م } 9 \text { مب }
$$

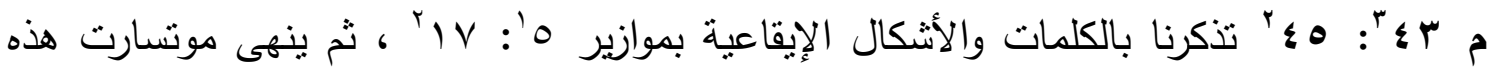

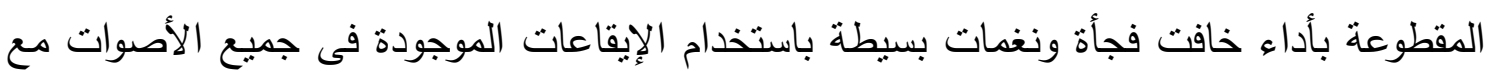

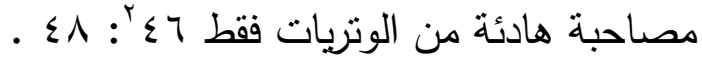

$$
\text { نتائج اللبحث :- }
$$

1 أسلوب موتسارت في تتاول صوت السوبرانو "في" في مقطوعة " الراحة الأبدية Requiem

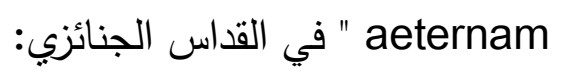

- تناول موتسارت صوت السوبرانو الفردي في منطقة صوتية مريحة تثمل سبع نغمات (صول

- - استخدم المؤلف في لحن السوبرانو مسافة الثالثة الصغيرة الصاعدة والهابطة . - استخم موتسارت التسلسل السلمي الصاعد والهابط بكثرة .

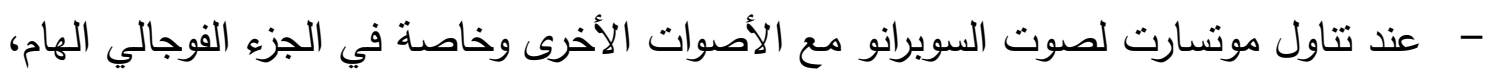

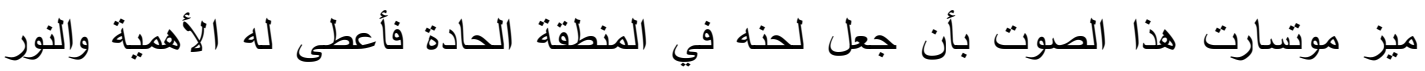

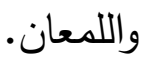

مجلة علوم وفنون الموسيقى - كلية التربية الموسبقية ـ المجلد الر ابع و الأربعون -

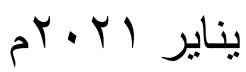


- - ترك موتسارت إلى المغنية حرية التعبير عن اللحن وعن معانى الكلمات، ولهذا لانجد الكثير من رموز التعبير

Requiem يفية تأليف موتسارت لصوت السوبرانو في مقطوعة "الراحة الأبدية aeternam

يجب على السوبرانو التي تؤدي هذه المقطوعة أن - ت تجيد نطق حروف وكلمات اللغة اللاتينية. - تتميز بصوت نقي ووقور وخالي من الإضافات والمجملات اللحنية التي تستخدم في بل كانتو .Bel Canto - - تكون متمرسة في الغناء الديني. - تكون لديها المهارة للتوحد والتكامل مع الأصوات الأخرى والأوركسترا. 


\section{REQUIEM}

\section{Introitus : Requiem aeternam}

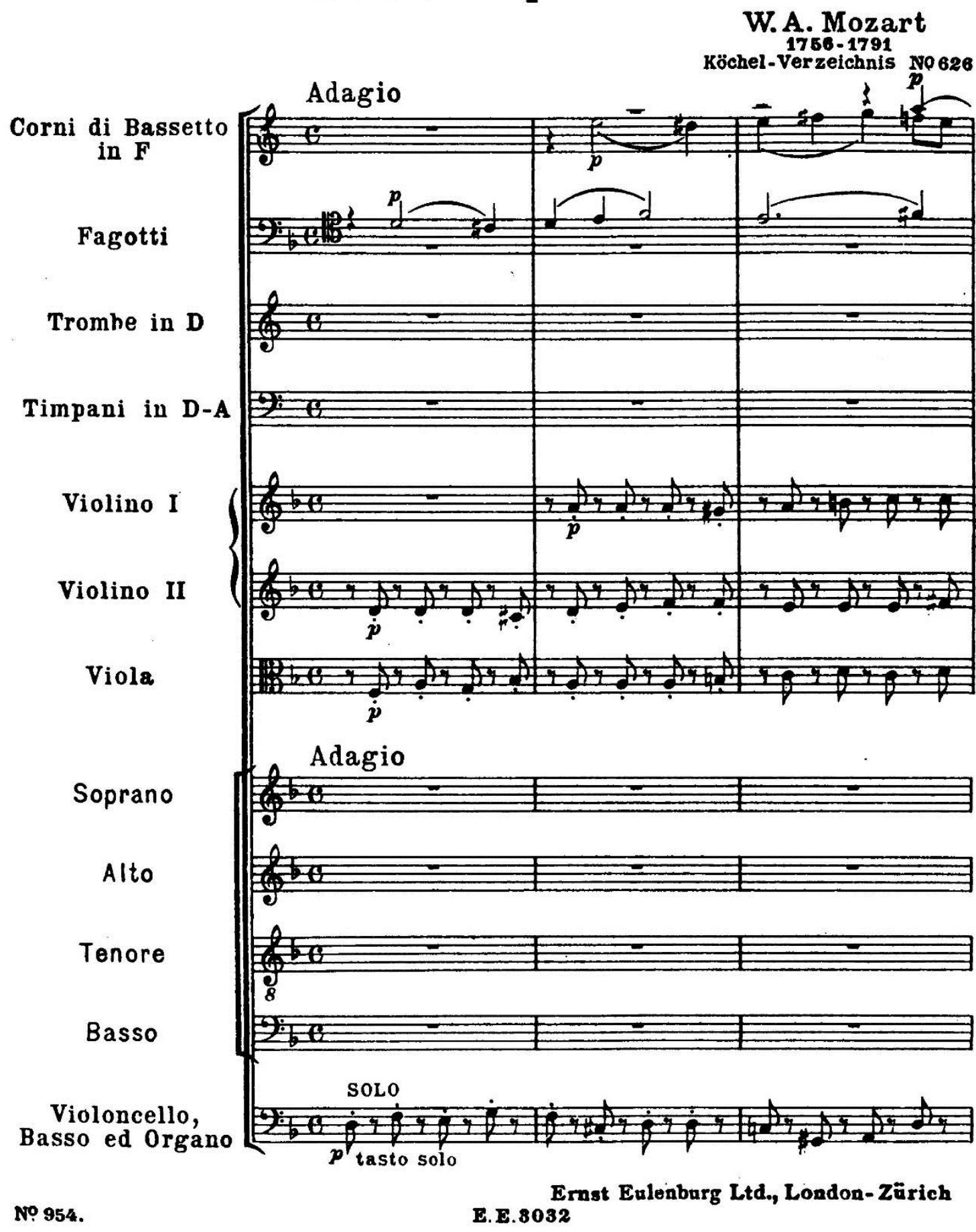



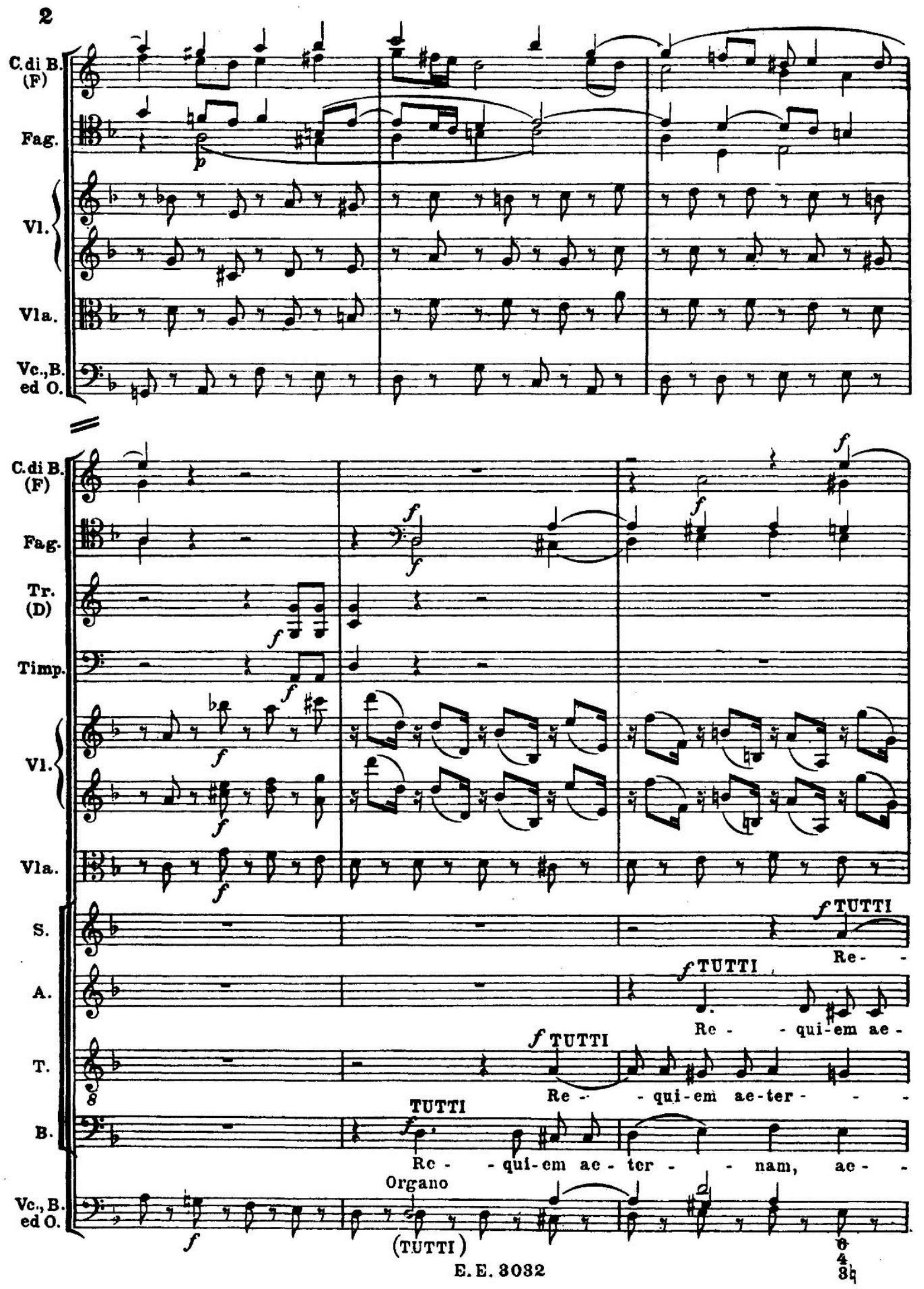

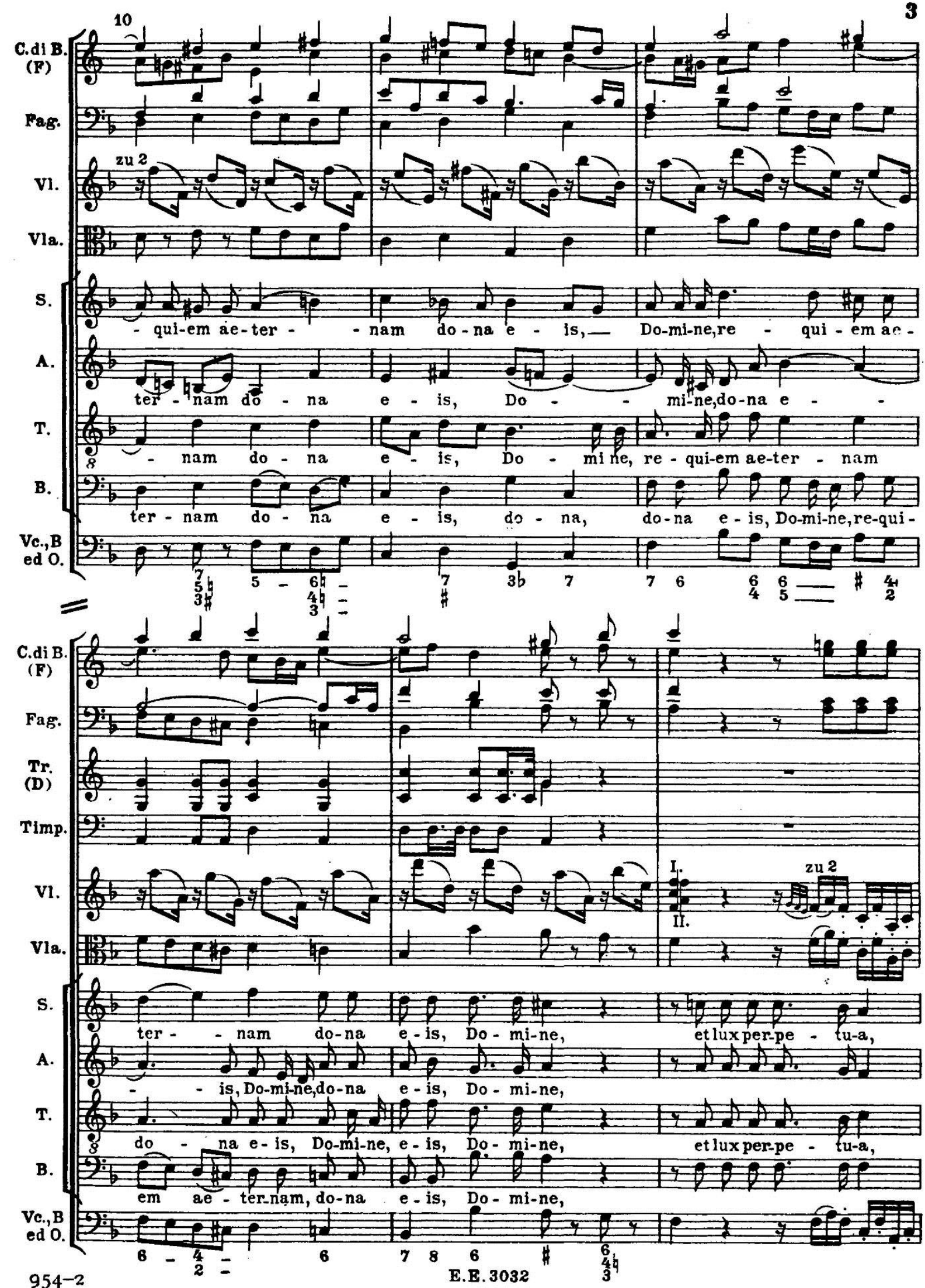


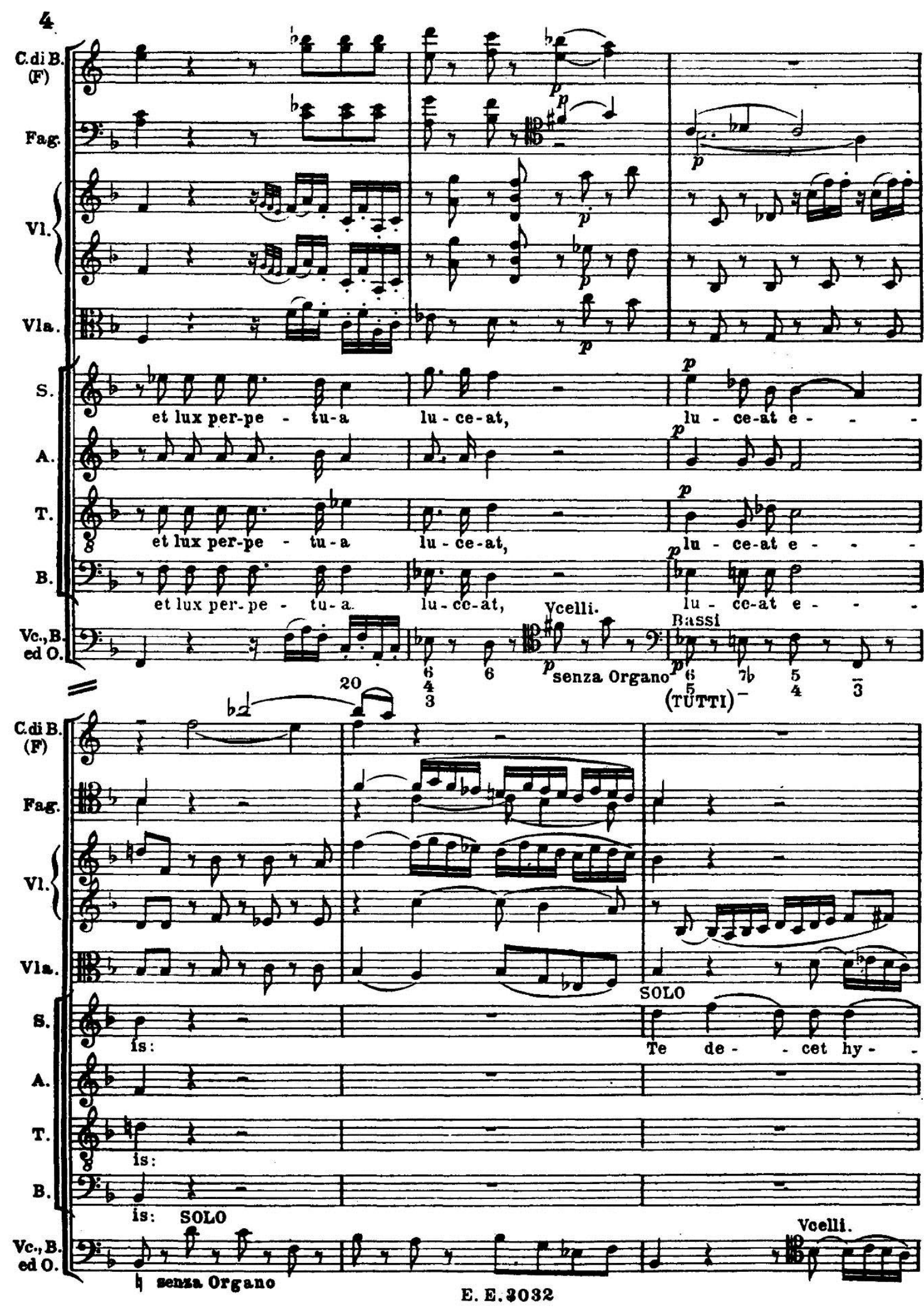



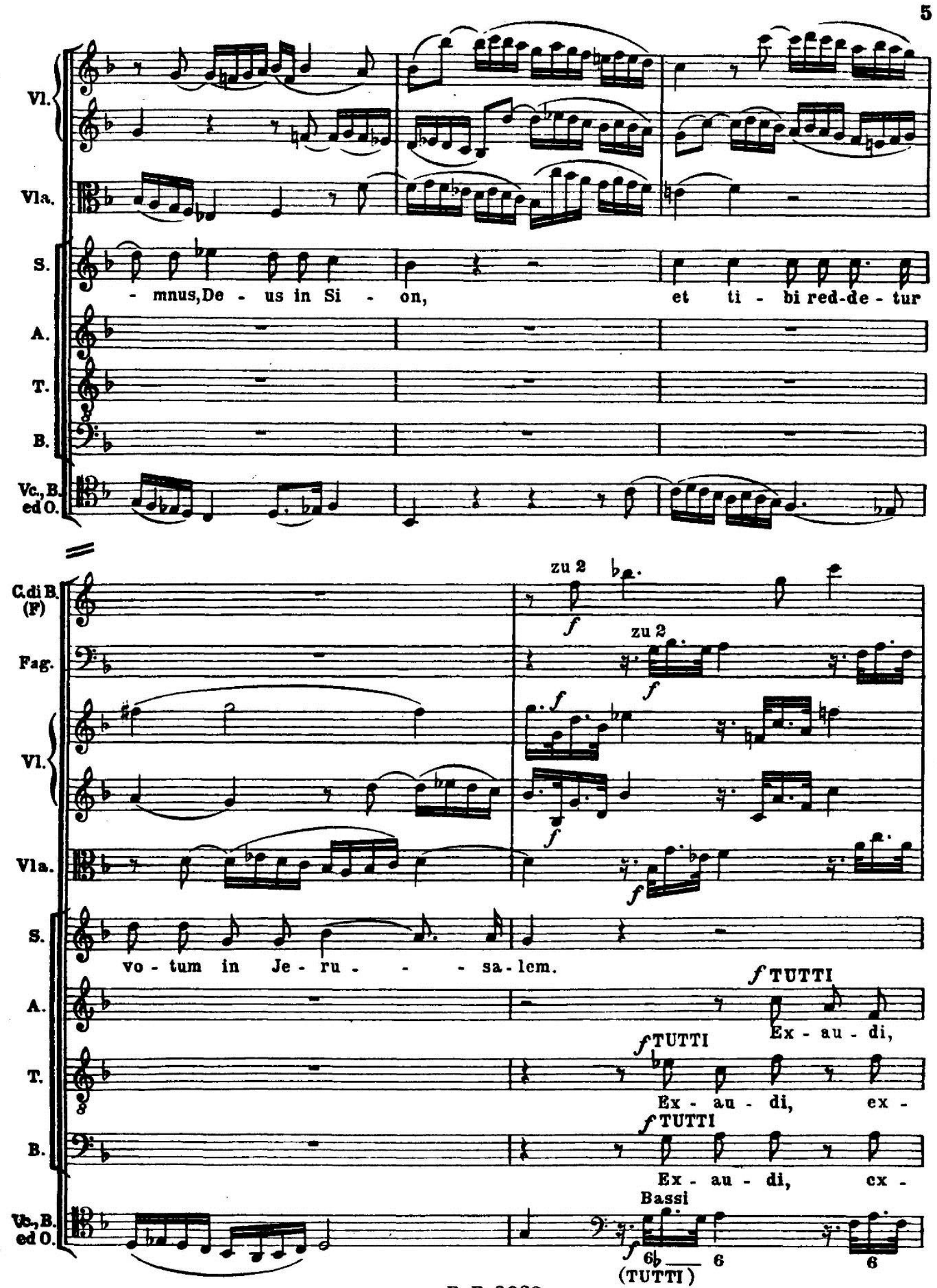

E. E. 3032 


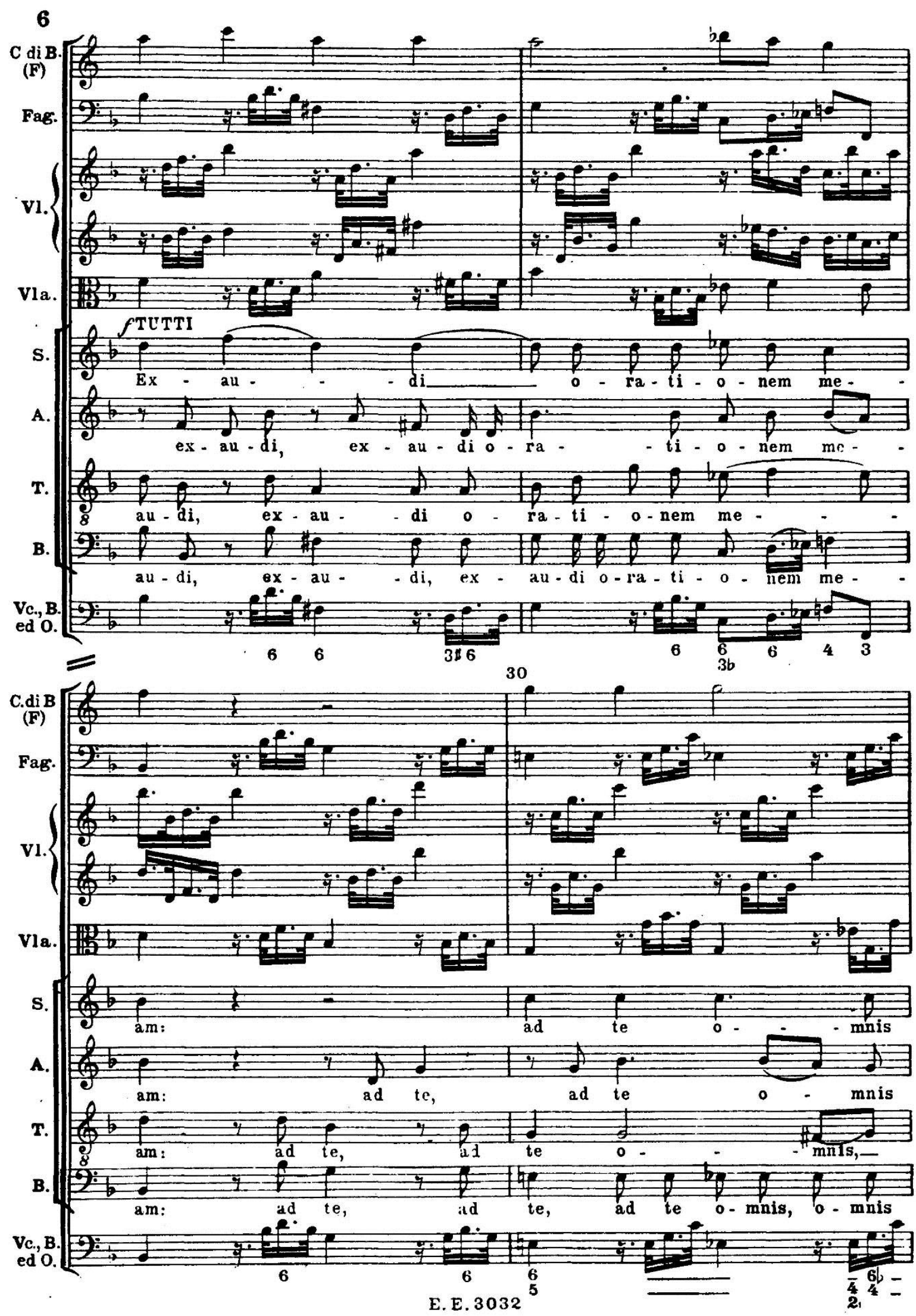



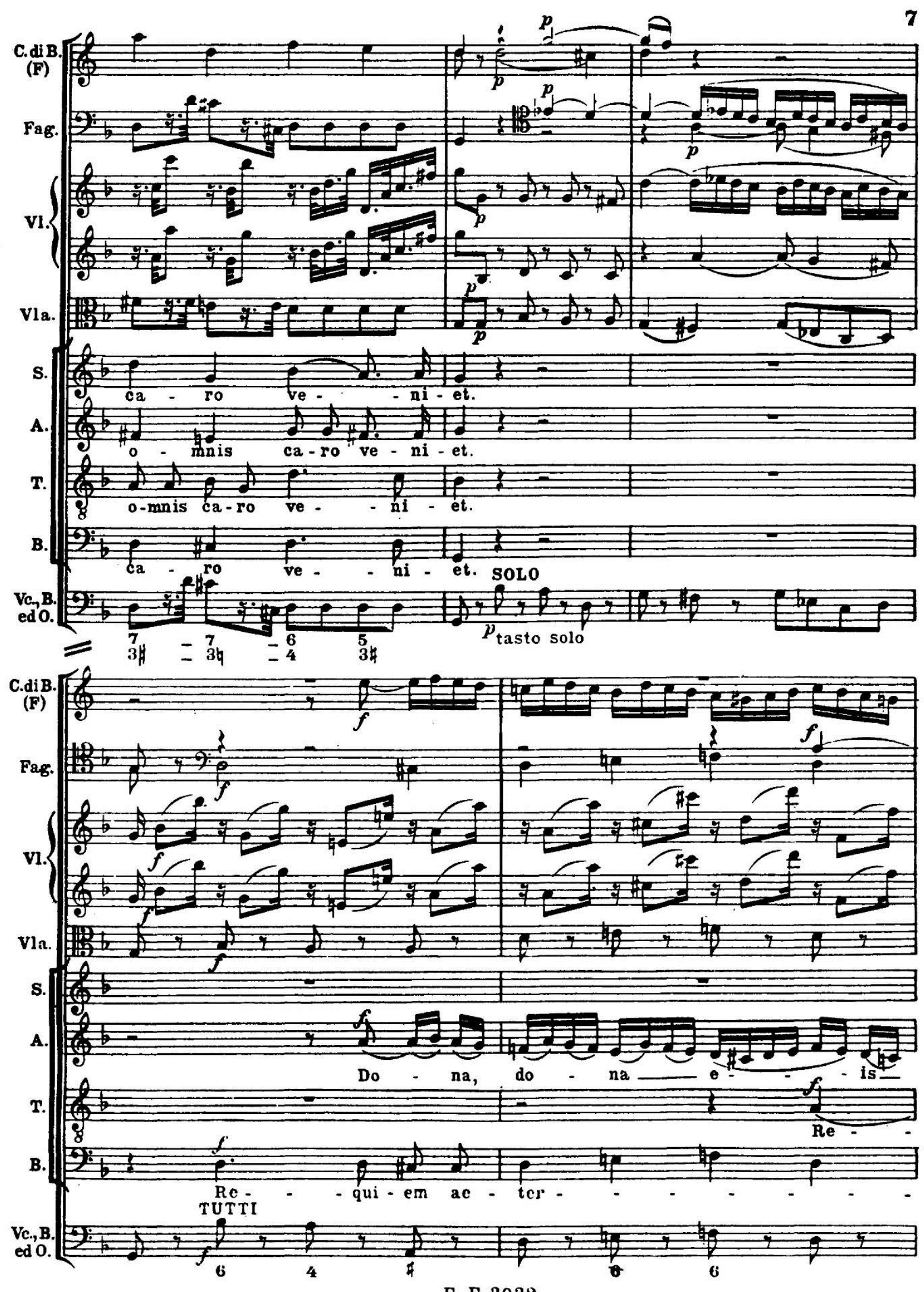

E. E. 3032 

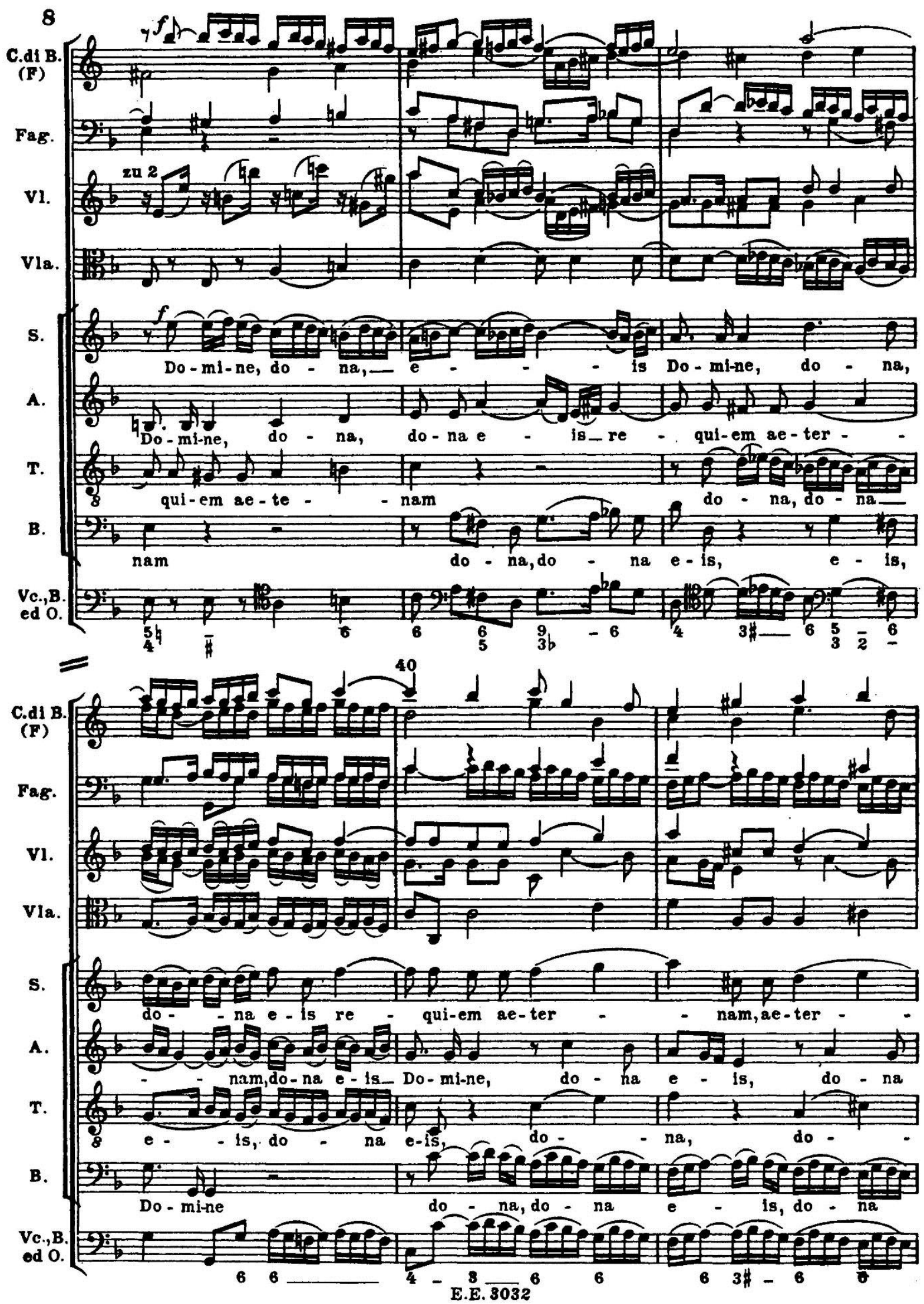


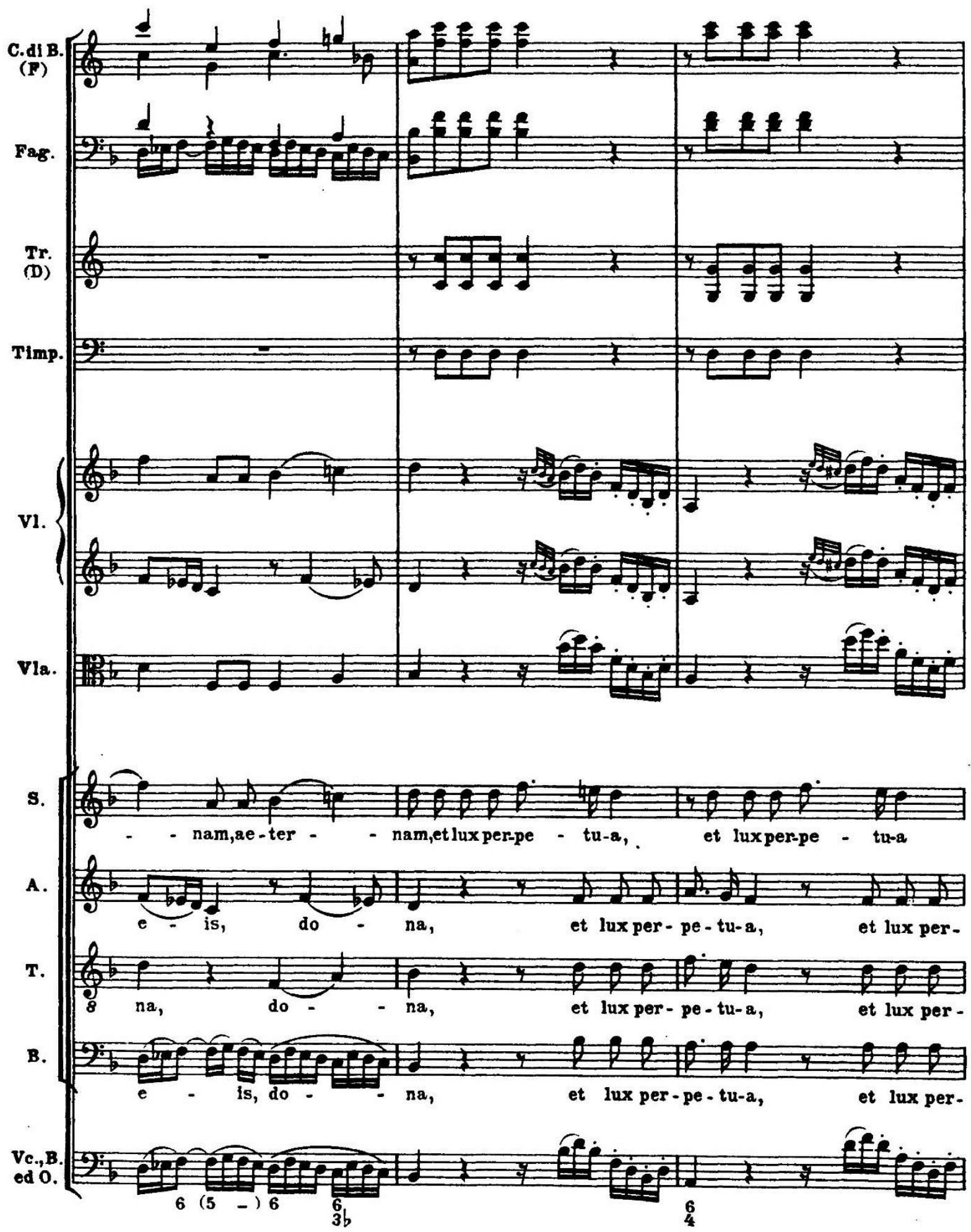

E. E. 3032 


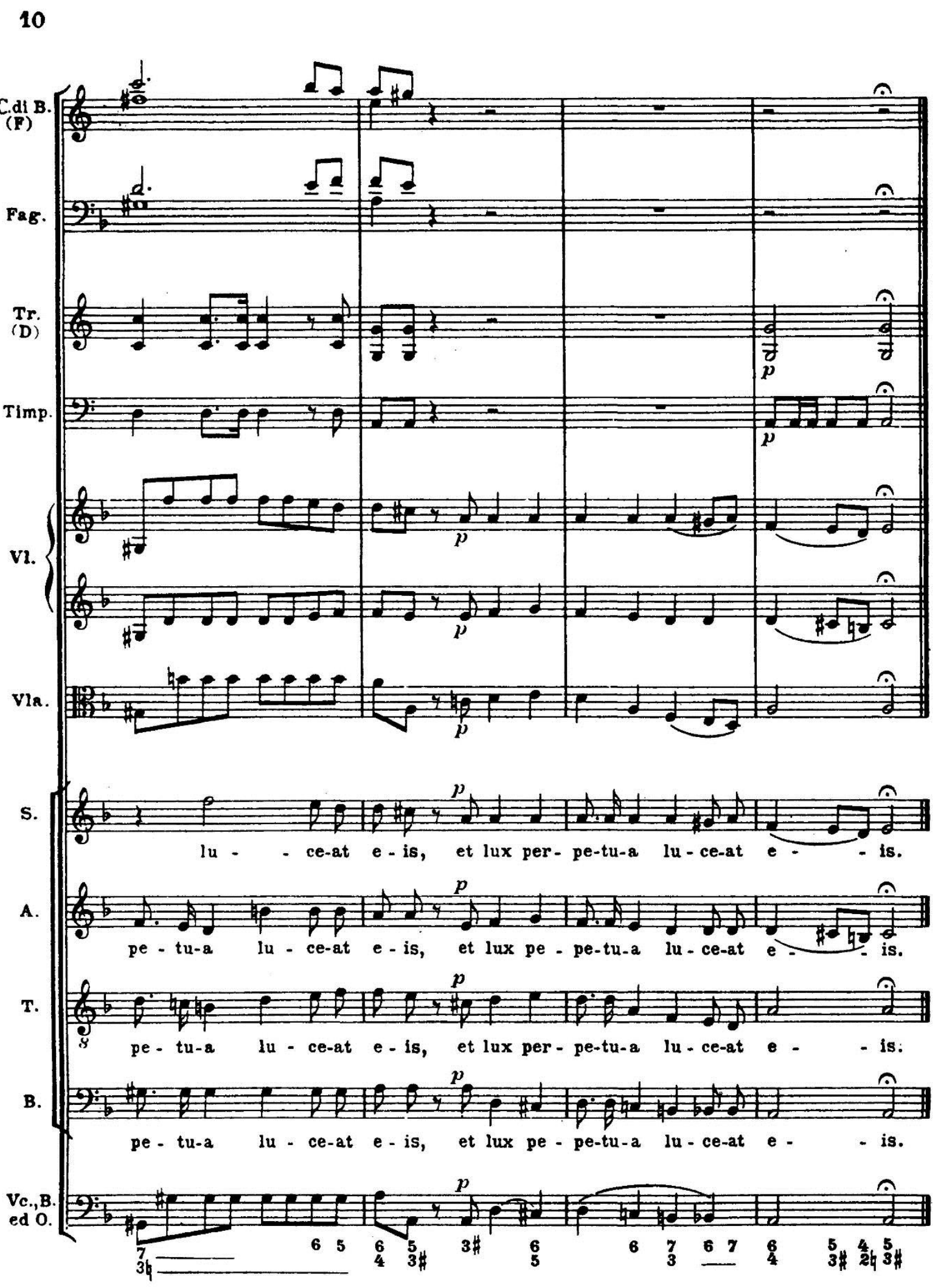

E. E. 3032 
() ثيودور • م • فيني : تاريخ الموسيقى العالمية، نرجمة سمحة الخولي وجمال عبد الرحيم، دار

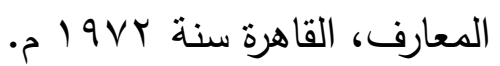

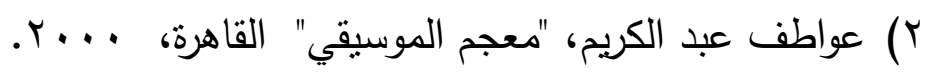

r) كورت زاكس ، تراث الموسيقى العالمية ، ترجمة سحة الخولي ، دار النهضة العربية، القاهرة، . $197 \varepsilon$

4) Alison Latham: The Oxford Companion of Music, Oxford university press, 2002, New York.

5) Appel Will: Harvard Dictionary of Music, liedi, Cambridge, London, 1972

6) Blom Eric (Edit.): Groves Dictionary of Music and Musicians, Fifth Edition, London, 1954, Macmillan, 1887

7) Christine Ammer: Dictionary of Music, fourth edition, 2004, by 1992 trust facctson, inc, NY 10001.

8) Daniel N. Leeson: THE Story of the Mozart Requiem, Opus Ultimum! Second Edition, Algora publishing, 2012, New York.

9) Richard Baker: The Hamlyn illustrated encyclopedia of music, edited by Alan Tsaacs \& Elizabeth Marten, The Hamlyn publishing group, limited 1982, 1990.

10) Rizzoli Ricordi: Encyclopedia Della Musica IV, Milano, 1963 - 1964

مجلة علوم وفنون الموسيقى - كلية التربية الموسيقية ـ المجلد الر ابع و الأربعون -

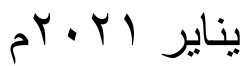


كيفية تناول موتسارت لصوت السويرانو في مقطوعة الراحة الأبدية من القداس الجنائزي ومتطلبات أداءه

تهتم الباحثة في هذه الدراسة على القاء الضوء على صوت السوبرانو لأغنية (الراحة الأبدية) من

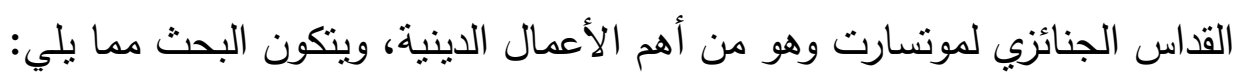

مشكلة البحث - أهداف البحث - أسئلة البحث - أدوات البحث - مات

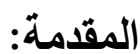

عينة البحث - مصطلحات البحث - الدراسات السابقة المرتبطة بموضوع البحث.

قداس الموتى لموتسارت - فولفجانج أماديوس موتسارت - أهم

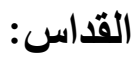

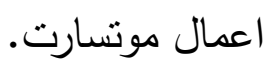

وتتنتل على العينة المنتقاة من القداس الجنائزي لمونسارت. الاراسة التحليلية: - n - n نتائج البحث والتوصيات: مراجع البحث - ملخص البحث باللغة العربية - ملخص البحث باللغة الإنجليزية. 


\section{Abstract \\ How Mozart has addressed and performed the Soprano in Requiem Aeternam Piece from his Requiem.}

In this study, the researcher is focusing on the voice of soprano for Mozart's requiem (aeternam), which is one of the most important sacred compositions. The research is consist of the following:

Introduction: The problem, objectives, research questions, research tools, research specimen, terminology, related previous researches.

The Mass: Mozart's requiem, Wolfgang Amadeus Mozart, Mozart's works

Analytical Study: The selected specimen from Mozart's requiem.

Results \& References, Arabic abstract, abstract.

Recommendations:

\footnotetext{
مجلة علوم وفنون الموسيقى - كلية التربية الموسيقية ـ المجلد الر ابع والأربعون -

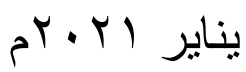

